\title{
Wettability of Irrigants used in Root Canal Treatment
}

\author{
Hélio P Lopes ${ }^{1}$, Adenilza R De Faria1, Flávio RF Alves ${ }^{1 *}$ and Carlos N Elias ${ }^{2}$
}

${ }^{1}$ Department of Endodontics, School of Dentistry, Estacio de Sa University, 580, Alfredo Baltazar, Rio de Janeiro, RJ, Brazil

${ }^{2}$ Department of Materials Science, Military Institute of Engineering, 80 Praça General Tiburcio , Rio de Janeiro, RJ, Brazil

\begin{abstract}
This study assessed the contact angle and the surface tension of different chemical solutions used in the chemomechanical preparation of root canals in order to calculate its wettability. The tested irrigants were: $2.5 \%$ sodium hypochlorite $(\mathrm{NaOCl}) ; 2 \%$ chlorhexidine $(\mathrm{CHX})$; BioPure $\mathrm{MTAD}^{\circledR}$; and $0.9 \%$ sterile physiological saline solution, as the control. A goniometer was used to measure the contact angle and the surface tension. Then the wettability of each solution was calculated using Young's equation. BioPure $M T A D^{\circledR}$ showed significantly higher contact angle $(p=0.002)$, compared to the other substances, which did not differ among themselves. As the surface tension, BioPure MTAD ${ }^{\circledR}$ showed significantly lower values $(p=0.001)$. As for $2.5 \%$ sodium hypochlorite, $2 \%$ chlorhexidine, and the control, chlorhexidine presented lowest surface tension $(p<0.01)$. BioPure MTAD ${ }^{\circledR}$ showed the best wettability in relation to the other tested irrigant, followed by two percent of $\mathrm{CHX}$ and $2.5 \% \mathrm{NaOCl}$.
\end{abstract}

Keywords: Contact angle; irrigants; surface tension; wettability; Young's equation

\section{Introduction}

The main objective of dental root canal treatment is to achieve a canal system free of microorganisms. The irrigant solutions used during treatment have the purpose of eliminating bacteria from infected root canals and promoting dissolution of the pulp tissue (a dense connective tissue). For decades, researchers have searched for antimicrobial agents that can effectively debride the root canal system. Until now the ideal chemical substance remains unknown [1-3].

Among the solutions available for root canal irrigation, two are the most commonly employed and one was more recent introduced as a promising irrigant. The first is the sodium hypochlorite $(\mathrm{NaOCl})$, a halogen substance, which has pronounced antimicrobial activity and tissue solvent capacity. Second is the chlorhexidine (CHX), which is a cationic bisbiguanida with antibacterial property, derived from its electrostatic attraction by the microbial cell wall, which damages the cell osmotic balance. CHX also has substantivity due to its capacity to bind in negatively charged surfaces on the oral cavity, such as the mineralizing dental tissue, acquired pellicle, mucous membranes and restorative materials, and be slowly released. Finally, the new intracanal irrigant is the Biopure $\mathrm{MTAD}^{\circ}$. This product is an aqueous solution of doxycycline, a broad-spectrum antibiotic; citric acid, a demineralizing agent; and polysorbate 80 detergent [4].

An irrigant solution used in root canal preparation must be in contact with the canal wall to promote the dissolution of organic tissues and disinfect the dentin and its tubules. During root canal instrumentation, untouched areas are a common problem even with superelastic rotary preparation. For example, studies with mesiobuccal root canals of maxillary first molars reported an average of untouched areas of $40.0 \%-47.4 \%$ [5-7]. For this reason, the solvent action and the antimicrobial activity in these areas are crucial to root canal disinfection.

A chemical solution for endodontic use must exhibit substantial wetness, which increases its solvent capability and improves antimicrobial activity in non-instrumented areas of the root canal system [8]. The wettability of a liquid can be assessed by measuring the contact angle of the liquid with a solid surface and its surface (or interfacial) tension. The present study was conducted to assess the contact angle and the surface tension of $\mathrm{NaOCl}$, $\mathrm{CHX}$ and Biopure $\mathrm{MTAD}^{\circ}$ in order to calculate there wettability.

\section{Material and Methods}

For this experiment, the following solutions were tested: $2.5 \%$ $\mathrm{NaOCl}\left(\mathrm{Q}^{\prime}\right.$ boa $^{\circledR}$, Indústrias Anhembi S/A, Osaco, SP, Brazil) $2 \%$ CHX (Fórmula Base Farmácia de Manipulação Ltda, Rio de Janeiro, RJ, Brazil), Biopure MTAD $^{\circ}$ (3\% doxycycline, $4.25 \%$ citric acid, and $0.5 \%$ polysorbate 80 ) (Dentsply, Tulsa, OK, USA), and $0.9 \%$ sterile physiological saline solution (control) (Equiplex, Aparecida de Goiânia, GO, Brazil).

\section{Measurement of contact angle}

The contact angle was measured on glass slides with a $1-\mu \mathrm{l}$ drop of the each chemical solution using a goniometer (First Ten Angstroms, Atlanta, GA, USA), which belongs to the Biomaterials Laboratory of the Military Institute of Engineering (IME, Rio de Janeiro, Brazil). For each chemical solution, 15 microscope glass slides with a size of $20 \times$ $20 \mathrm{~mm}$ and thickness of 0.13-0.17 mm (Lamedid Comercial e Serviços LTDA, Barueri, SP, Brazil) were used.

After being formed, the droplet was placed on the slide as soon as it came in contact with the surface and detached from the syringe. Each droplet was photographed after being placed on the slide, and the image was digitized with a scanner. Then, the contact angle between the droplet and the slide was calculated by the software Fta32_Video (First Ten Angstroms, Atlanta, GA, USA) using the tangent of the angle between the droplet and the solid surface.

\section{Measurement of surface tension}

The surface tension of each solution was measured with the pending droplet method, using the same software described above. In this method, the liquid droplet stays attached to the goniometer

*Corresponding author: Flávio RF Alves, Faculty of Dentistry, Estacio de Sa University, Av . Alfredo Baltazar da Silveira , 580 / coverage , Bandeirantes Playground, 22790-710, Rio de Janeiro, RJ, Brazil, Tel: 5521 984967137; E-mail: flavioferreiraalves@gmail.com

Received January 05, 2015; Accepted February 02, 2015; Published February 07, 2015

Citation: Lopes HP, De Faria AR, Alves FRF, Elias CN (2015) Wettability of Irrigants used in Root Canal Treatment. Dentistry 5: 283. doi:10.4172/2161-1122.1000283

Copyright: @ 2015 Lopes HP, et al. This is an open-access article distributed under the terms of the Creative Commons Attribution License, which permits unrestricted use, distribution, and reproduction in any medium, provided the original author and source are credited. 
syringe, and the surface tension is determined by fitting the shape of the drop (in a captured video image) to the Young-Laplace equation, which relates surface tension to drop shape. The software does this automatically. In Young-Laplace equation $y\left(1 / R_{1}+1 / R_{2}\right)=\Delta P, y$ is the surface tension, $R_{1}$ and $R_{2}$ are the two principal radii of curvature of the surface, and $\Delta P$ is the pressure difference across the interface.

In order to measure the surface tension, 10 droplets of each substance were used, which were then put in a glass receptacle and discarded. The droplets were formed by $1 \mu \mathrm{l}$ of the solution. Next, they were photographed, the images were digitized with a scanner, and the software calculated the surface tension. The results are expressed in millinewtons per meter $(\mathrm{mN} / \mathrm{m})$.

\section{Calculation of wettability}

In order to assess the wettability of the solutions, Young's equation was used: $\gamma_{\mathrm{LV}} \cos \theta=\gamma_{\mathrm{SV}}-\gamma_{\mathrm{SL},}$ where $\gamma_{\mathrm{SL}}$ represents the surface tension between the solid and the liquid, $\gamma_{\mathrm{SV}}$ and $\gamma_{\mathrm{LV}}$ are the surface tension of the solid and the surface tension of the liquid in equilibrium with the air, respectively, and $\theta$ is the contact angle (Figure 1). For this purpose, the contact angle means computed for each solution and the surface tension means were used. The surface tension value of the solid in relation to the air used in this study was $1.05 \mathrm{~J} / \mathrm{m}^{2}$ in accordance with a previous study [9]. The surface tension of the solid in relation to the air $\left(\gamma_{\mathrm{SV}}\right)$ was converted into millinewtons per meter in order to apply the equation.

The parametric one-way analysis of variance (ANOVA) was used to identify significant differences among the irrigant solutions. Tukey's post hoc was used to determine which irrigant were significantly different. The significance level was set at $\mathrm{p}<0.05$.

\section{Results}

Table 1 shows the mean values of contact angle registered for the different irrigant solutions. The variance analysis (ANOVA) revealed that there is a statistically significant difference among the tested irrigants $(p=0.002)$. Thus, the Tukey test showed that 2\% CLX, $2.5 \%$ $\mathrm{NaOCl}$, and the control substance were not different from each other but that they had a significantly lower contact angle than Biopure MTAD $^{\circledR}$.

Table 2 shows the mean values of surface tension registered for the different irrigant solutions. There is a statistically significant difference among the tested irrigants $(p=0.001)$. The Tukey test showed that Biopure $\mathrm{MTAD}^{\circledR}$ presented a surface tension significantly lower than that of $2 \% \mathrm{CLX}, 2.5 \% \mathrm{NaOCl}$, and the control substance. As for $2 \%$ CLX, $2.5 \% \mathrm{NaOCl}$ and the control, CLX had the lowest surface tension $(\mathrm{p}<0.01)$.

The wettability of the substances, which were analyzed using Young's equation, is expressed in Table 3. Biopure $\mathrm{MTAD}^{\circ}$ presented the highest wettability, followed by $2 \% \mathrm{CHX}, 2.5 \% \mathrm{NaOCl}$, and the control solution.

\section{Discussion}

The contact angle is an indicator of the wettability of irrigants. The experimental values of the contact angle can be obtained by direct measurement of the tangent of the angle between the liquid droplet and the solid surface of the substrate [10].

A low value of the contact angle indicates that the liquid has a high wettability, whereas a high value indicates a low wettability. It has been determined that if the contact angle is less than $90^{\circ}$, there is wetting of

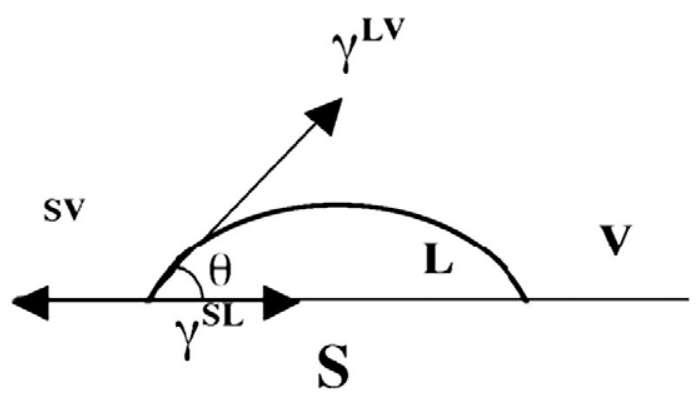

Figure 1: Schematic diagram of the wettability calculation using Young's equation.

\begin{tabular}{|c|c|}
\hline Solution & Contact Angle \\
\hline Chlorhexidine $2 \%$ & $20.83^{\circ}\left(7.23^{\circ}\right)^{\mathrm{a}}$ \\
\hline $\mathrm{NaOCI} 2.5 \%$ & $21.25^{\circ}\left(6.04^{\circ}\right)^{\mathrm{a}}$ \\
\hline Biopure MTAD $\AA$ & $28.34^{\circ}\left(5.07^{\circ}\right)^{\mathrm{b}}$ \\
\hline Control & $17.50^{\circ}\left(4.46^{\circ}\right)^{\mathrm{a}}$ \\
\hline Different letters indicate statistically different values $(\mathrm{p}<0.05)$ \\
\hline
\end{tabular}

Table 1: Average contact angle values of the assayed substances.

\begin{tabular}{|c|c|}
\hline Solution & Surface Tension $(\mathbf{m N} / \mathbf{m})$ \\
\hline Chlorhexidine $2 \%$ & $146.61(12.67)^{\mathrm{b}}$ \\
\hline $\mathrm{NaOCl} 2.5 \%$ & $177.39(14.49)^{\mathrm{a}}$ \\
\hline Biopure MTAD® & $90.55(2.82)^{\mathrm{c}}$ \\
\hline Control & $186.87(13.16)^{\mathrm{a}}$ \\
\hline Different letters indicate statistically different values $(\mathrm{p}<0.05)$ \\
\hline
\end{tabular}

Table 2: Average surface tension values $(\mathrm{mN} / \mathrm{m})$ of the assayed substances.

\begin{tabular}{|c|c|c|c|c|}
\hline Solutions & NaOCl at 2.5\% & CLX2\% & Biopure MTAD $尺$ & Control \\
\hline Results & 885.03 & 913.66 & 970.32 & 872.48 \\
\hline \multicolumn{5}{|c|}{ Table 3: Wettability values $(\mathrm{mN} / \mathrm{m})}$.
\end{tabular}

the surface; if it is greater than $90^{\circ}$, there is no wetting; and a contact angle equal to zero represents complete wetting [11]. In the present study all tested substances presented contact angles at least three times lower than $90^{\circ}$.

The present study evaluated the contact angle and surface tension of the tested irrigants on glass slides and then the wettability was calculated using a mathematics equation. Some studies evaluated the effect of pre-treatment of dentin samples with different irrigants on the contact angle of the substance with the dentin, in other words, the wettability of the surface was the one assessed [12-14]. In one of these studies, the values for contact angles were significantly reduced after the pre-treatment of the dentin for 10 min with $5.25 \% \mathrm{NaOCl}$ and $3 \%$ $\mathrm{H}_{2} \mathrm{O}_{2}$ in comparison with $17 \%$ EDTA. The latter substance showed no significant difference compared to the control (distilled water) [12]. Another study using similar methodology did not find difference in wettability after pre-treatment of dentin with $2.5 \% \mathrm{NaOCl}$ or $17 \%$ EDTA [14]. Despite the relevance of testing the wettability of dentin treated with different substances, the difficulty of standardizing this surface/substrate may explain the discrepancy among the results from different studies. In the present study, the standardization of the surface allowed the comparison of the wettability of solutions controlling this bias.

In this work, surface tension was measured using the pending droplet method. Recently, this approach was used to assess the effect of the addition of benzalkonium chloride to sodium hypochlorite on 
its wetting properties, contact angle, and surface energy [15]. For the Biopure $\mathrm{MTAD}^{\circledR}$ versus $\mathrm{NaOCl}$, the present study confirmed a previous report that the surface tension of Biopure $\mathrm{MTAD}^{\circ}$ is lower than the $\mathrm{NaOCl}$, despite the fact that the tested concentration of $\mathrm{NaOCl}$ used in this study was half of the used in an early study (5,25\%) [8], In relation to CHX, there has been no previous report about surface tension of this irrigant at a concentration of $2 \%$. In the present study, $\mathrm{CHX}$ assumed the intermediate position regarding the surface tension.

Surface tension is considered to be one of the most important factors in determining the wettability of a solution. Consequently, it is expected that the solution with the lowest surface tension can wet the walls of the root canal more extensively than those with a higher value can [16]. This hypothesis was confirmed in the present study.

Wettability is the tendency of a given fluid to spread over or adhere to a solid surface. The wetting is correlated to the contact angle $\theta$, while the spreading is related to the extension of the projected area [1]. This property is important for the chemical solution to penetrate the main and lateral canals, as well as the dentinal tubules, and it is dependent upon the surface tension $[8,17]$. In the present study, Biopure MTAD ${ }^{\circ}$ was the substance with the highest wettability followed by $2.5 \% \mathrm{NaOCl}$ and $2 \%$ CHX. Another study pointed a result of surface tension favorable to Biopure $\mathrm{MTAD}^{\circledR}$ compared to $\mathrm{NaOCl}[8]$.

In the present work, the selected irrigants were tested pure, without the addition of any substance. Surface-active agents can reduce the surface tension of some irrigants up to $50 \%$, increasing their wettability on a surface. This is a good strategy to increase the ability of the irrigant to penetrate the root canal dentin and, consequently, increase its antimicrobial action. Temperature and $\mathrm{pH}$ also affect the surface tension of solutions. Increasing the temperature or reducing the $\mathrm{pH}$ decreases the surface tension level $[14,18,19]$.

Biopure $\mathrm{MTAD}^{\circ}$ was launched in the market with the purpose of combining a higher detergent effect with strong antimicrobial efficacy. Although the wettability of Biopure $\mathrm{MTAD}^{\circledR}$ is superior than the other solutions tested, studies show that its antimicrobial and antifungal activity is lower than the $5 \%$ or $6 \% \mathrm{NaOCl}$ and $2 \% \mathrm{CHX}$ $[20,21]$. However, one study showed that MTAD was significantly more effective in killing E. faecalis than $\mathrm{NaOCl}$ when the solutions were diluted [22]. For these reasons some authors proposed the association of the antimicrobial peptide nisin in the composition of Biopure MTAD ${ }^{\circledR}$. They found a significantly improvement on the bactericidal activity of Biopure $\mathrm{MTAD}^{\circledR}$ against E. faecalis [23]. Currently, the use of Biopure $\mathrm{MTAD}^{\circledR}$ as intracanal irrigant is more restrict to final irrigation, after the use of $\mathrm{NaOCl}$ as main irrigant [24]. There is no doubt that the ideal irrigant solution must present good wettability associated to effective antimicrobial activity.

\section{Conclusion}

BioPure $\mathrm{MTAD}^{\circledR}$ showed the best wettability in relation to the other tested irrigant, followed by two percent of $\mathrm{CHX}$ and $2.5 \% \mathrm{NaOCl}$.

\section{Acknowledgement}

This study was supported by grants from Fundação Carlos Chagas Filho de Amparo à Pesquisa do Estado do Rio de Janeiro (FAPERJ), a Brazilian Governmental Institution. The authors disclose no conflicts of interest.

\section{References}

1. Shabahang S, Pouresmail M, Torabinejad M (2003) In vitro antimicrobia efficacy of MTAD and sodium hypochlorite. J Endod 29: 450-452.

2. Machnick TK, Torabinejad M, Munoz CA, Shabahang S (2003) Effect of MTAD on flexural strength and modulus of elasticity of dentin. J Endod 29: 747-750.
3. Shabahang S, Aslanyan J, Torabinejad M (2008) The substitution of chlorhexidine for doxycycline in MTAD: the antibacterial efficacy against strain of Enterococcus faecalis. J Endod 34: 288-290.

4. Mohammadi Z, Soltani MK, Shalavi S (2014) An update on the management of endodontic biofilms using root canal irrigants and medicaments. Iran Endod J 9: 89-97.

5. Hübscher W, Barbakow F, Peters OA (2003) Root-canal preparation with FlexMaster: canal shapes analysed by micro-computed tomography. Int Endod J 36: $740-747$

6. Peters OA, Peters Cl, Schönenberger K, Barbakow F (2003) ProTaper rotary root canal preparation: effects of canal anatomy on final shape analysed by micro CT. Int Endod J 36: 86-92.

7. Zhao D, Shen Y, Peng B, Haapasalo M (2013) Micro-computed tomography evaluation of the preparation of mesiobuccal root canals in maxillary first molars with Hyflex CM, Twisted Files, and K3 instruments. J Endod 39: 385-388.

8. Giardino L, Ambu E, Becce C, Rimondini L, Morra M (2006) Surface tension comparison of four common root canal irrigants and two new irrigants containing antibiotic. J Endod 32: 1091-1093.

9. Hara S, Izumi S, Kumagai T, Sakai S (2005) Surface energy, stress and structure of well-relaxed amorphous silicon: A combination approach of ab initio and classical molecular dynamics. Surface Science 585: 17-24.

10. Kumar G, Prabhu KN (2007) Review of non-reactive and reactive wetting of liquids on surfaces. Adv Colloid Interface Sci 133: 61-89.

11. Kontakiotis EG, Tzanetakis GN, Loizides AL (2007) A comparative study of contact angles of four different root canal sealers. J Endod 33: 299-302.

12. Hu X, Ling J, Gao Y (2010) Effects of irrigation solutions on dentin wettability and roughness. J Endod 36: 1064-1067.

13. Dogan Buzoglu H, Calt S, Gümüsderelioglu M (2007) Evaluation of the surface free energy on root canal dentine walls treated with chelating agents and $\mathrm{NaOCl}$. Int Endod J 40: 18-24.

14. Yılmaz Z, Aktemur S, Buzoglu HD, Gümüsderelioglu M (2011) The effect of temperature and $\mathrm{pH}$ variations on the surface tension of EDTA solutions. J Endod 37: 825-827.

15. Bukiet F, Couderc G, Camps J, Tassery H, Cuisinier F, et al. (2012) Wetting properties and critical micellar concentration of benzalkonium chloride mixed in sodium hypochlorite. J Endod 38: 1525-1529.

16. Yilmaz Z, Basbag B, Buzoglu HD, Gümüsderelioglu M (2011) Effect of low surface-tension EDTA solutions on the wettability of root canal dentin. Oral Surg Oral Med Oral Pathol Oral Radiol Endod 111: 109-114.

17. Palazzi F, Morra M, Mohammadi Z, Grandini S, Giardino L (2012) Comparison of the surface tension of $5.25 \%$ sodium hypochlorite solution with three new sodium hypochlorite-based endodontic irrigants. Int Endod J 45: 129-135.

18. Wang Z, Shen Y, Ma J, Haapasalo M (2012) The effect of detergents on the antibacterial activity of disinfecting solutions in dentin. J Endod 38: 948-953.

19. Abou-Rass M, Patonai FJ Jr (1982) The effects of decreasing surface tension on the flow of irrigating solutions in narrow root canals. Oral Surg Oral Med Oral Pathol 53: 524-526.

20. Prabhakar J, Senthilkumar M, Priya MS, Mahalakshmi K, Sehgal PK, et al. (2010) Evaluation of antimicrobial efficacy of herbal alternatives (Triphala and green tea polyphenols), MTAD, and $5 \%$ sodium hypochlorite against Enterococcus faecalis biofilm formed on tooth substrate: an in vitro study. J Endod 36: 83-86.

21. Ruff ML, McClanahan SB, Babel BS (2006) In vitro antifungal efficacy of four irrigants as a final rinse. J Endod 32: 331-333.

22. Torabinejad M, Shabahang S, Aprecio RM, Kettering JD (2003) The antimicrobial effect of MTAD: an in vitro investigation. J Endod 29: 400-403.

23. Tong Z, Huang L, Ling J, Mao X, Ning Y, et al. (2014) Effects of intracanal irrigant MTAD Combined with nisin at sub-minimum inhibitory concentration levels on Enterococcus faecalis growth and the expression of pathogenic genes. PLoS One 6, e90235.

24. Aranda-Garcia AR, Guerreiro-Tanomaru JM, Faria-Júnior NB, Chavez Andrade GM, Leonardo RT, et al. (2012) Antibacterial effectiveness of several irrigating solutions and the Endox Plus system - an ex vivo study. Int Endod J 45: 1091-1096. 